\title{
COMPARISON OF HEMATOPOIESIS IN THE FETUS AND DURING RECOVERY FROM PERNICIOUS ANEMIA
}

\author{
TOGETHER WITH A CONSIDERATION OF THE RELATIONSHIP OF FETAL \\ HEMATOPOIESIS TO MACROCYTIC ANEMIA OF PREGNANCY \\ AND ANEMIA IN INFANTS 1, 2
}

\author{
By M. M. WINTROBE ANd H. B. SHUMACKER, JR. ${ }^{3}$ \\ (From the Department of Medicine and the Surgical Hunterian Laboratory, \\ the Johns Hopkins University, Baltimore)
}

(Received for publication July 3, 1935)

It is well known that the red corpuscles of the newborn are larger than those of the normal adult. Little study has been made, however, of the size and number of the corpuscles of the fetus. The purpose of this communication is to describe certain observations on the size and number of the red cells in the blood of the fetus and newborn of several species of mammal; namely, man, rabbit, pig, rat, cat and dog. In the species examined, it has been found that low erythrocyte counts and large red corpuscles are consistently found in the fetus, and that the younger the fetus the lower is the red cell count and the larger the red corpuscles. As compared with the blood of the adult of the same species, there is in the fetus what may for descriptive purposes be spoken of as "anemia" of the macrocytic type. As the fetus develops, the erythrocyte count rises and the mean size of the red corpuscles diminishes in a manner which reminds one of the changes which take place in the blood of patients with pernicious anemia during the response to liver therapy.

\section{REVIEW OF LITERATURE}

Malassez (1) in 1875 and Cohnstein and Zuntz (2) in 1884 observed that the erythrocyte count in the early stages of development of the fetus (rabbit, dog, sheep) is low, and that it gradually increases. In 1889, the former measured the diameters of the red corpuscles (3) of a human fetus of four and one-half months and found the cells to be larger than those of adult blood. The exceptionally large size of the earliest nucleated red corpuscles of the embryos of mammals was noted much earlier than 1889, however, for Milne-Edwards (1857) (4) quotes Prévost, Wagner, Gulliver and Bischoff in this connection.

1 Aided in part by a grant from the Committee on Scientific Research of the American Medical Association.

2 Read at the meeting of the American Society for Clinical Investigation, Atlantic City, N. J., May 6, 1935. 8 Stephen C. Clark Fellow in Surgery.
Jolly $(5,6)$ studied the blood of rat fetuses and newborn, and pointed out that in this species the red cell count even at birth is only about one-fourth of that of the adult whereas in the rabbit and human newborn the erythrocyte count is essentially the same as in the adult. Nicholas and Bosworth (7) observed an increase of hemoglobin from 30 to 65 per cent in rat fetuses ranging from the twelfth day of the fetal period to the newborn stage. Kindred and Corey (8) found increasing erythrocyte counts in rat fetuses 15.4 to $43.0 \mathrm{~mm}$. in length (sixteenth to twenty-second day). Smith (9) reported diameter measurements as well as red cell counts in rats from two days before birth until the adult stage was reached. She found a gradual increase in the number of corpuscles until the twenty-third day of life when their number began to increase rapidly, attaining the adult values at about three months of age. Throughout this whole period the mean diameter of the red cells, their color index and variability, and the proportion of reticulocytes, gradually decreased.

Knoll $(10,11)$ has recorded successively increasing red cell counts in human fetuses one to six months of age.

Zeidberg (12) studied rabbit fetuses and found an increase in hemoglobin from 8 to 12 grams during the last third of pregnancy (twenty-second to thirty-second day) and an increase in packed red corpuscles from 28 to 42 per cent. He noted, moreover, that the proportion of basophilic red corpuscles decreased during this period from 28 per cent to 4 per cent. von Deseö (13) seems to have been the first to measure the mean volume and hemoglobin content of the red corpuscles in fetal blood. In 25 beef fetuses ranging from $2 \frac{1}{2}$ to 9 months of age he observed, as the age of the fetuses advanced, an increase in the erythrocyte count from 3.74 to 7.80 million, in hemoglobin from 7.65 to 10.83 grams and in volume of packed red corpuscles from 34.0 to $42.3 \mathrm{cc}$., whereas the mean corpuscular volume decreased from 90.9 to 54.2 c. $\mu$., mean corpuscular hemoglobin fell from 20.5 to 14.0 micromicrograms and mean corpuscular hemoglobin concentration fluctuated between 20.9 and 25.6 per cent.

\section{MATERIAL AND METHODS}

Through the courtesy of the Department of Obstetrics, blood was obtained from 12 obviously non-viable human fetuses removed by hysterectomy. Blood was secured by cardiac puncture immediately following removal of the 
fetus. The approximate age of the fetuses was estimated from the crown-rump length and the entire length on the basis of the charts of Keibel and Mall (14) and Streeter (15). Blood was also obtained, by jugular puncture, from 3 premature infants at the Harriet Lane Home. The values for the blood of newborn infants which are used for Figure 4 represent the average of 31 determinations made immediately after birth, and 18 determinations made at intervals until the twenty-fifth day of life (16).

Rabbits of blue-black Dutch stock and of mixed laboratory stocks were mated in our own laboratory and, since the buck and doe were together for three or four hours only, the age of the rabbit fetuses studied could be estimated with accuracy. The fetuses were removed by hysterectomy and the blood immediately obtained. Whenever possible, blood was secured by cardiac puncture. In the case of very small fetuses the heart was cut open and the blood was drawn into a capillary pipet as it welled out. In order to obtain sufficient amounts of blood, in a number of instances the blood of several fetuses from the same uterus was mixed.

The blood of rat fetuses was obtained in the same way as that of the rabbit fetuses. The rats were not deliber- ately mated, however, and the age of the fetuses had therefore to be calculated from weight and crown-rump length on the basis of data published by Donaldson (17). The age of newborn rats was determined from accurate litter records. The rats were of an inbred laboratory stock on a standard diet (18).

Pig fetuses were obtained in a neighboring abbatoir. The uteruses of pregnant sows were brought to the laboratory immediately after the animals had been slaughtered and the fetal blood was there collected without delay. In no instances had clotting commenced, and in some of the pig fetuses the heart was still beating when the blood was withdrawn. Blood was frequently collected from the umbilical cord, it having been found that the erythrocytic content of blood obtained in this way was the same as that of blood taken from the heart. In the case of the smaller pig fetuses, blood was taken directly from the heart in the manner already described. The age of the pig fetuses was estimated from their weight and crownrump length on the basis of Warwick's data (19). Blood of newborn pigs was obtained by cardiac puncture on animals at the U. S. Research Center, Beltsville, Maryland, through the courtesy of Dr. Hugh McPhee.

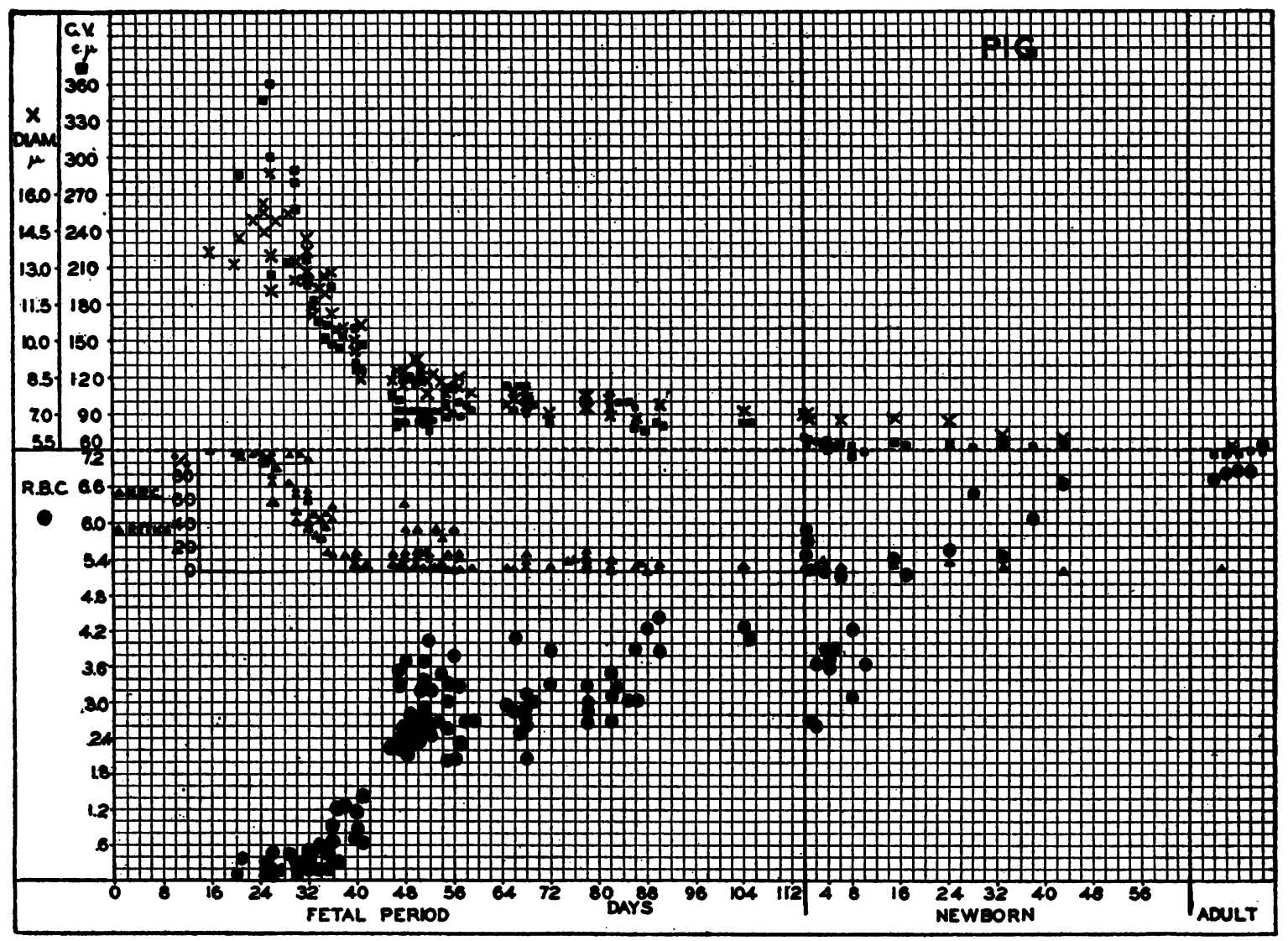

Fig. 1. ERythrocyte Counts ( $\odot$, Millions per c.mm.), Mean Corpuscular Volume ( $\mathbf{a}$, Cubic Microns), Mean Diameter in Wet Preparations ( $X$, Microns), Proportion of Nucleated Red Corpuscles (a) and of Reticulocytes $(\Delta)$ in the Blood of 98 Pig fetuses, 22 Newborn Pigs, and 5 Adult Pigs. 


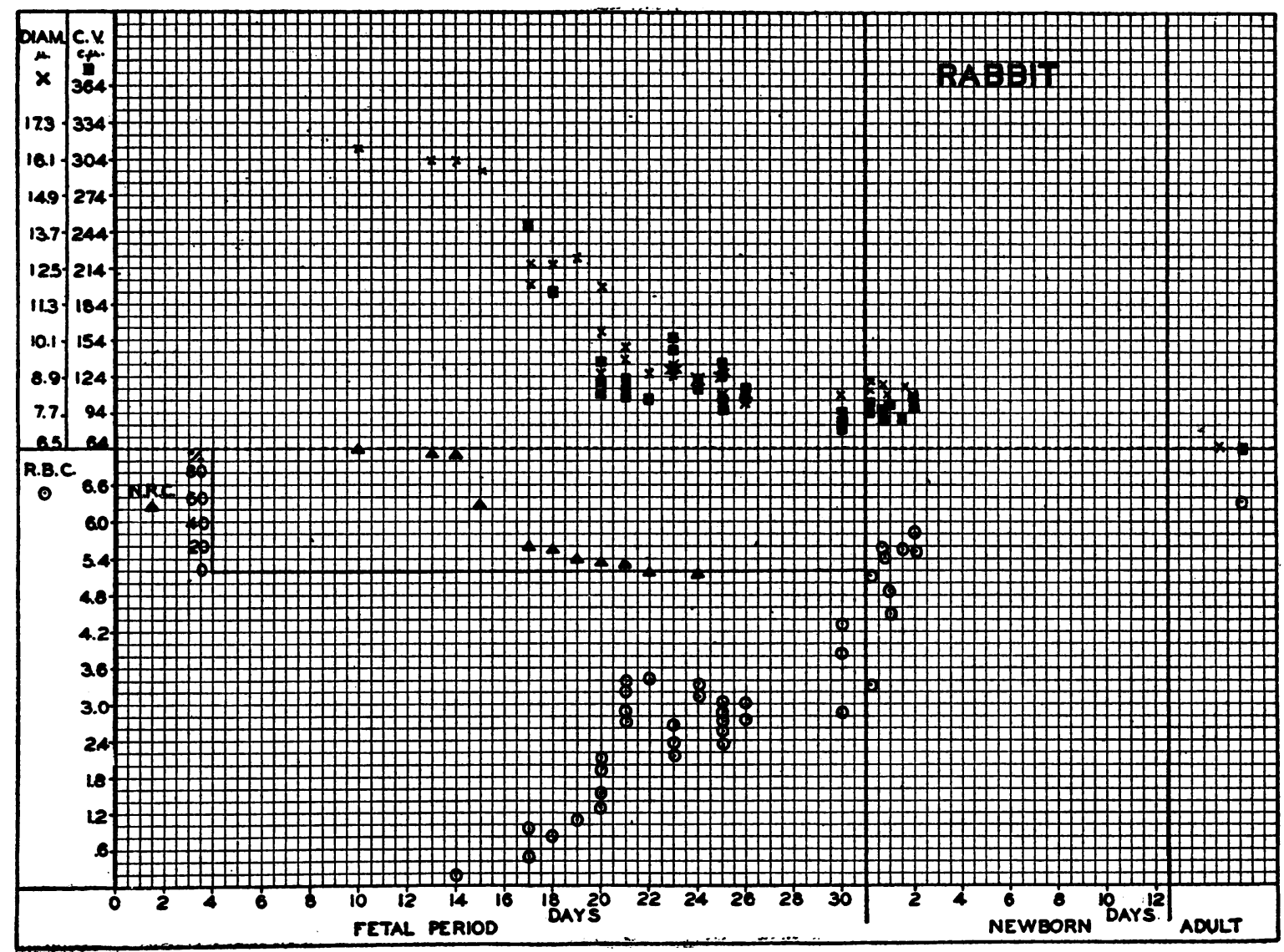

Fig. 2. Erythrocyte Counts ( $\odot$, Millions per c.mm.), Mean Corpuscular Volume (a, Cubic Microns), Mean Diameter in Wet Preparations ( $X$, Microns) and Proportion of Nucleated Red Corpuscles (A) in the Blood of 34 Rabbit Fetuses and 8 Newborn Rabbits, Compared with Average Values for the Adult RaBBit.

Blood of newborn dogs and cats was obtained by cardiac puncture on animals born in the laboratory. The age of fetuses was estimated from weight and crown-rump length $(20,21)$.

The blood was collected either in heparin or without an anticoagulant, it having been found that coagulation is extremely slow and imperfect in the blood of young fetuses. Hemolyzed specimens were discarded.

Fresh blood preparations and blood smears were made, and two diameters of 25 to 100 unselected red corpuscles in the wet and in the dried, stained films (Wright's stain) were measured by means of a calibrated ocular micrometer. The proportion of nucleated corpuscles was determined in the stained preparations. Reticulocyte counts were made in wet preparations to which a small quantity of brilliant cresyl blue ( 1 per cent in normal saline) had been added. Erythrocyte counts (two in each instance), hemoglobin and hematocrit determinations, and calculations of the mean volume and hemoglobin content of the red corpuscles were made as described elsewhere $(22,23)$.

Two chief sources of error must be kept in mind in in- terpreting the results of these studies: (1) except in the case of the rabbit fetuses, the age of fetuses has been estimated from data for length and weight and is therefore only approximate; (2) when the fetuses were very small, such minute amounts of blood were available that values in the smaller fetuses for hemoglobin, volume of packed red cells, and mean volume and hemoglobin content of the red corpuscles cannot be considered as representing the same degree of accuracy as is possible when studying the blood of adults (23). Erythrocyte counts, however, may be considered as being quite accurate in almost all instances, and diameter measurements represent of course the same degree of accuracy for fetuses of all sizes.

\section{OBSERVATIONS}

Details of the blood studies are published elsewhere (24). Erythrocyte counts, mean corpuscular volume, mean diameter (in wet preparations) and the proportion of nucleated red corpuscles and 
reticulocytes in the blood of fetuses and newborn of the pig, rabbit, rat and man are shown in Figures 1 to 4 . The data are so plotted that a comparison with the values found in the adult may be readily made. It will be noted that the erythrocyte count is very low in young fetuses and increases as the fetus develops. The mean volume and mean diameter of the red corpuscles are at first very much greater than in the adult, and decrease as the red cell count rises.

In a few instances marked differences in the erythrocyte counts of litter mates, even greater than one million cells, were encountered. Usually, however, the counts fell within a range of 300,000 cells per c.mm. It is of interest that the mean sizes of the red corpuscles of litter mates agreed without exception within limits of technical varia- tion even when great differences in red cell counts occurred.

Even at birth the erythrocyte count was found to be lower than that of the adult, and the corpuscles were larger than is normal for the adult. This was found to be especially true of the rat, as Jolly had noted (5), but was observed also in the blood of the other species of mammals examined. Our studies in the rat indicate that almost two months elapse before the values of the adult are attained.

Comparison of the blood of the fetus with macrocytic anemia in the human adult

In many respects the changes which have been observed in the blood of patients with pernicious anemia under the influence of liver therapy, are

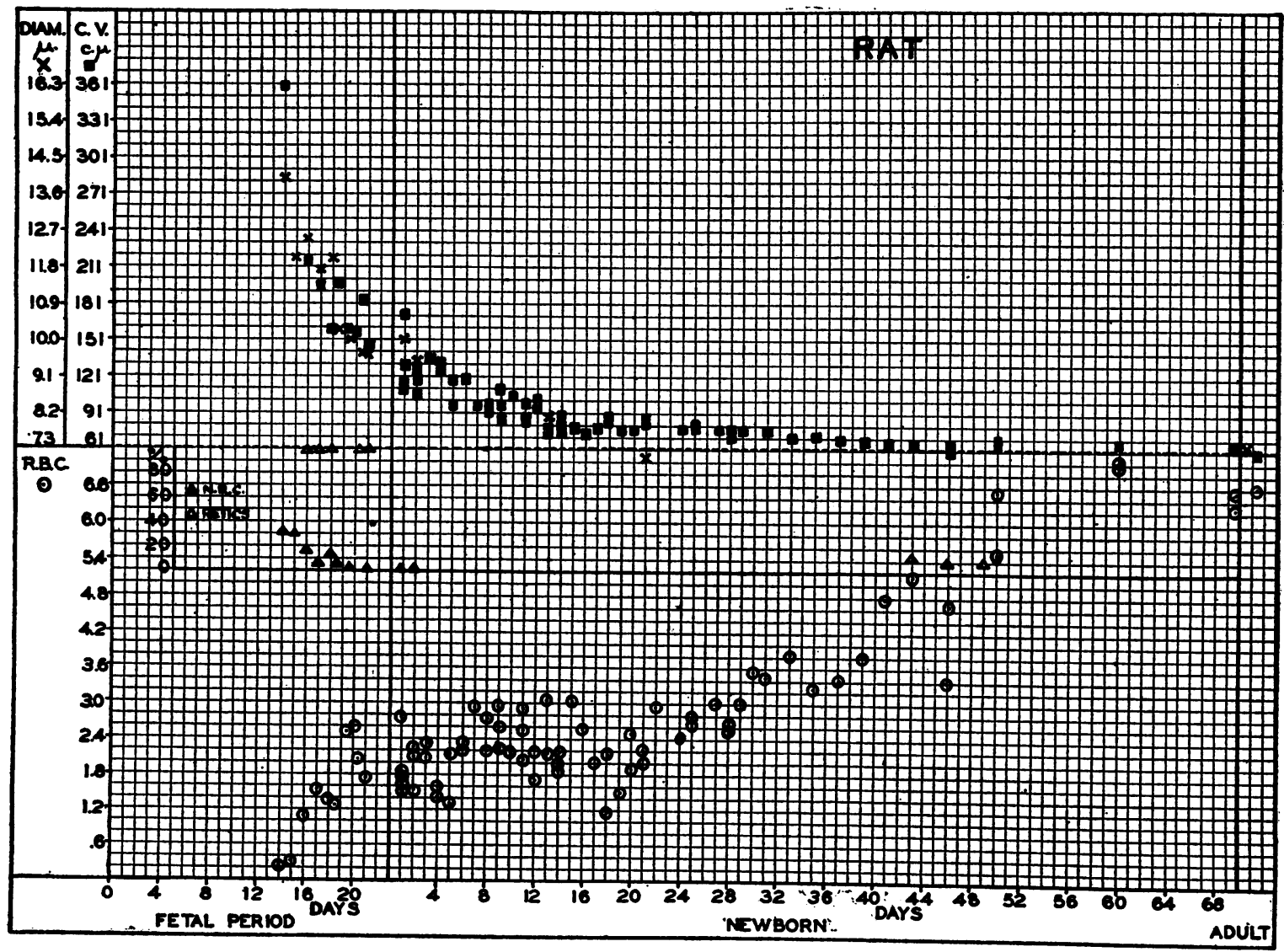

Fig. 3. Erythrocyte Counts ( $\odot$, Millions per c.mm.), Mean Corpuscular Volume ( $\square$, Cubic Microns), Mean Diameter in Wet Preparations ( $\times$, Microns), Proportion of Nucleated Red Corpuscles ( $(\Delta)$ and of Reticulocytes $(\Delta)$ in the Blood of 11 Rat Fetuses and 67 Newborn Rats, Compared with Average Values for the Adult Rat. 


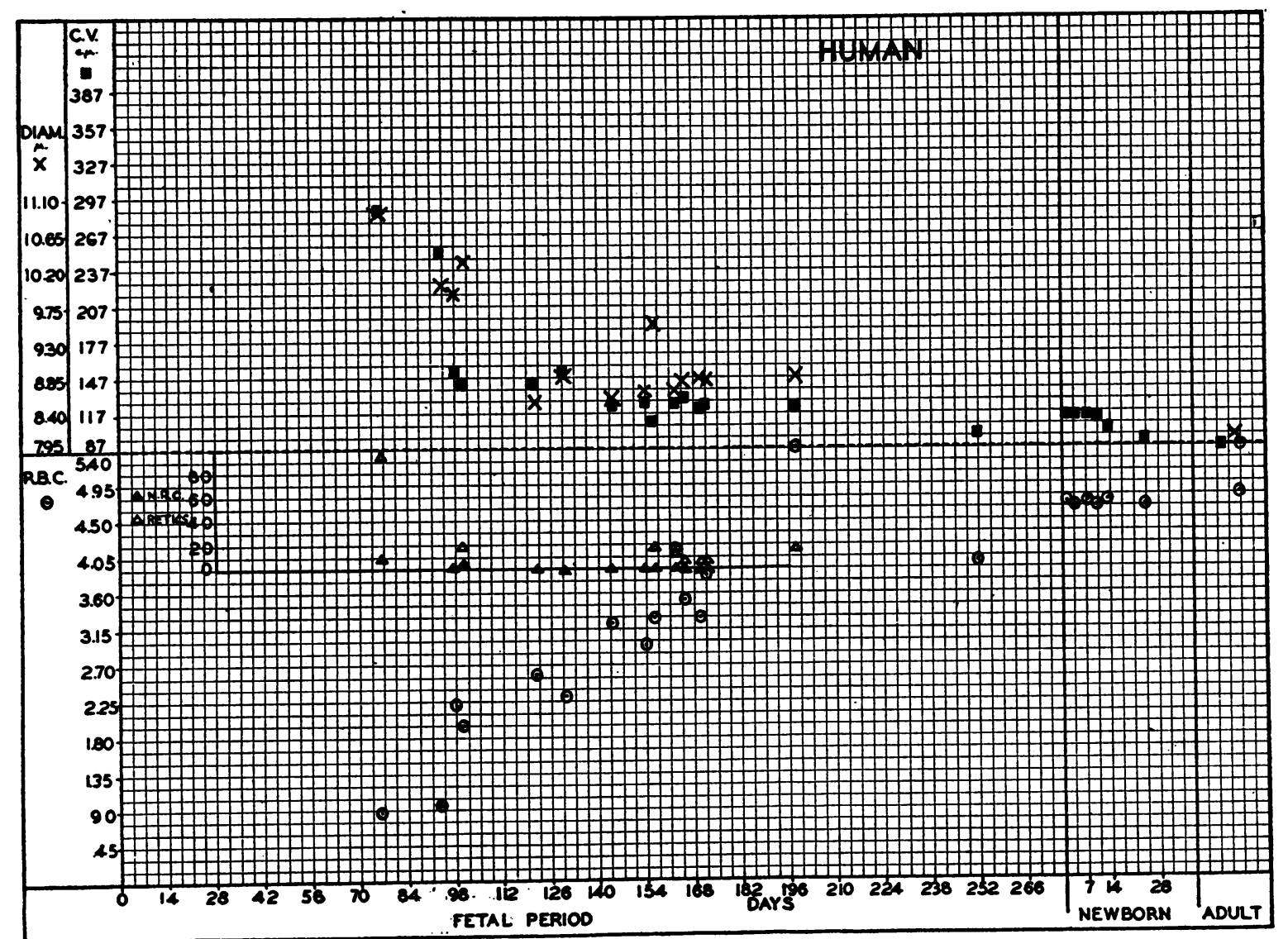

Fig. 4. Erythrocyte Counts ( $\odot$, Millions per c.mm.), Mean Corpuscular Volume ( $\square$, Cubic Microns), Mean Diameter in Wet Preparations ( $X$, Microns), Proportion of Nucleated Red Corpuscles ( 4 ) and of Reticulocytes $(\triangle)$ in the Blood of 12 Human Fetuses and 3 Premature Infants, Compared with Average Values for 49 Full Term Newborn Infants and the Normal Adult.

similar to those which take place during the normal development of the blood corpuscles in the fetus. The senior author has described elsewhere (25) the variations which take place in mean corpuscular volume in cases of pernicious anemia during liver treatment. There is a striking resemblance between the curves which represent the changes in pernicious anemia and those shown in Figures 1 to 4.

Superficial examination suggests that the macrocytosis observed in the blood of the fetus is much greater than that of pernicious anemia. Mean corpuscular volumes as great as even five and six times the normal have been found in the blood of very young fetuses, whereas in pernicious anemia it is unusual to find an increase in mean corpuscular volume to as much as even twice normal. It must be borne in mind, however, that in pernicious anemia erythrocyte counts below 1 million cells are quite unusual and values lower than 0.5 million are rarely, if ever, encountered. The extremely high values for mean corpuscular volume were observed only in those instances in which the erythrocyte counts were as low as 5 per cent of those of the adult, and less; that is, they correspond in terms of human blood to red cell counts lower than 250,000 per c.mm. When corpuscular volumes corresponding to similar reductions below the normal adult red cell count are compared (see Figures 5, 6 and 7) the degree of macrocytosis in the fetus is found to be quite similar to that of pernicious anemia.

Not only is the mean size of the red corpuscles in fetal blood greater than that of the red cells of the adult, but a great degree of anisocytosis is present. As the fetus develops, this anisocytosis 


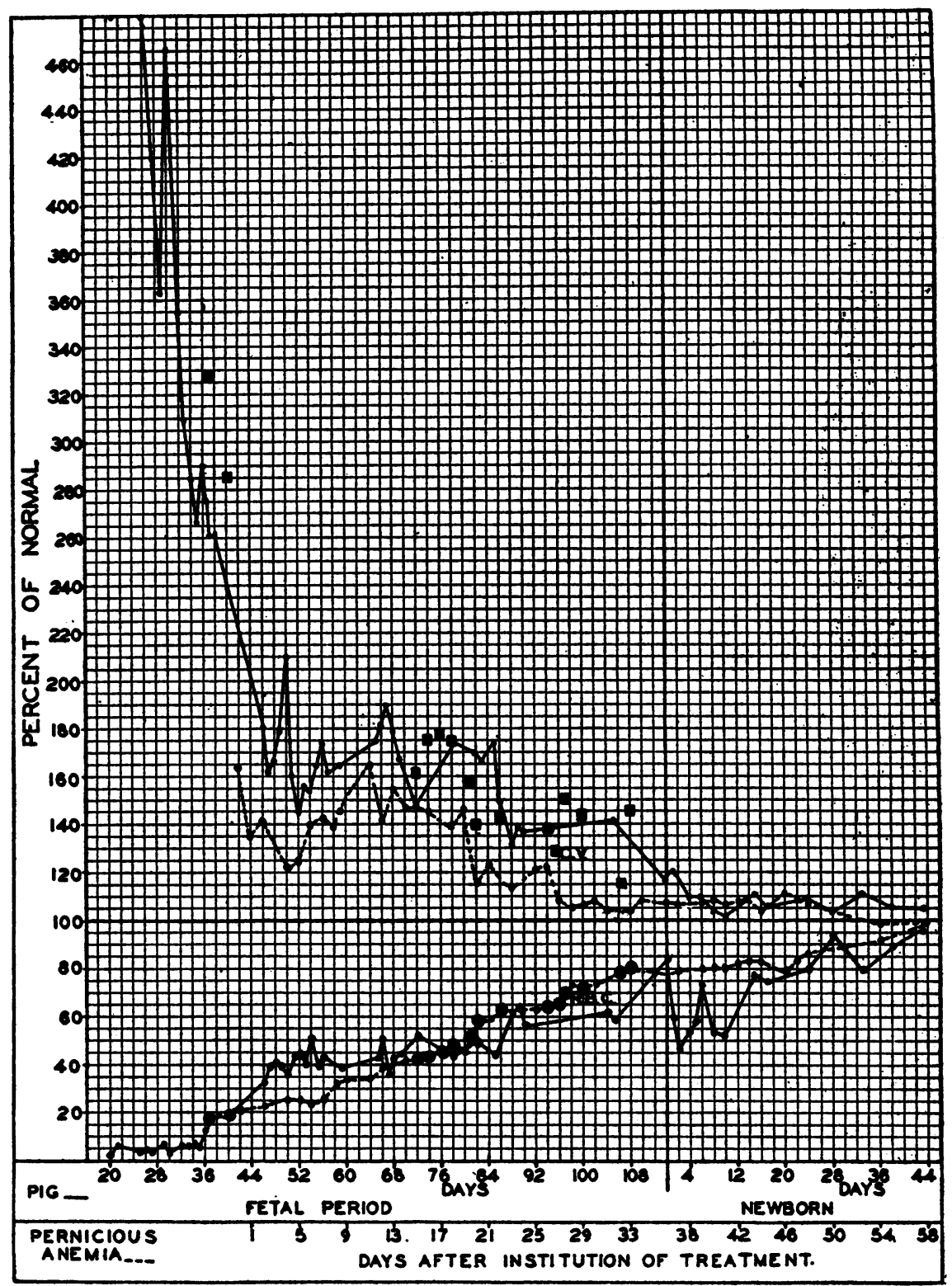

Fig. 5. Comparison of Variations in the Erythrocyte Count (R.B.C.) and mean Corpuscular Volume (C.V.) of Pig and Human fetuses of Different Ages with Those of a Patient Receiving Liver Therapy for Pernicious Anemia.

All values have been calculated in proportion to the normal for the adult of each species. The complete line represents the blood of the pig fetuses. The values recorded are the averages of those obtained for each day of fetal life, shown in Figure 1. The interrupted line represents the blood of a case of pernicious anemia. This curve commences in a position corresponding to the forty-third day of pig fetal life because at this time the red cell count of the pig fetus was the same in proportion to the normal red cell count of the adult pig, as was the erythrocyte count of the patient in proportion to that of the normal human adult.

The large black circles represent erythrocyte counts and the black squares mean corpuscular volumes of human fetuses, expressed in proportion to the normal human adult values. The red cell counts of the human fetuses are superimposed on the erythrocyte curve for the case of pernicious anemia, and the mean corpuscular volumes are placed in the corresponding position above them. 


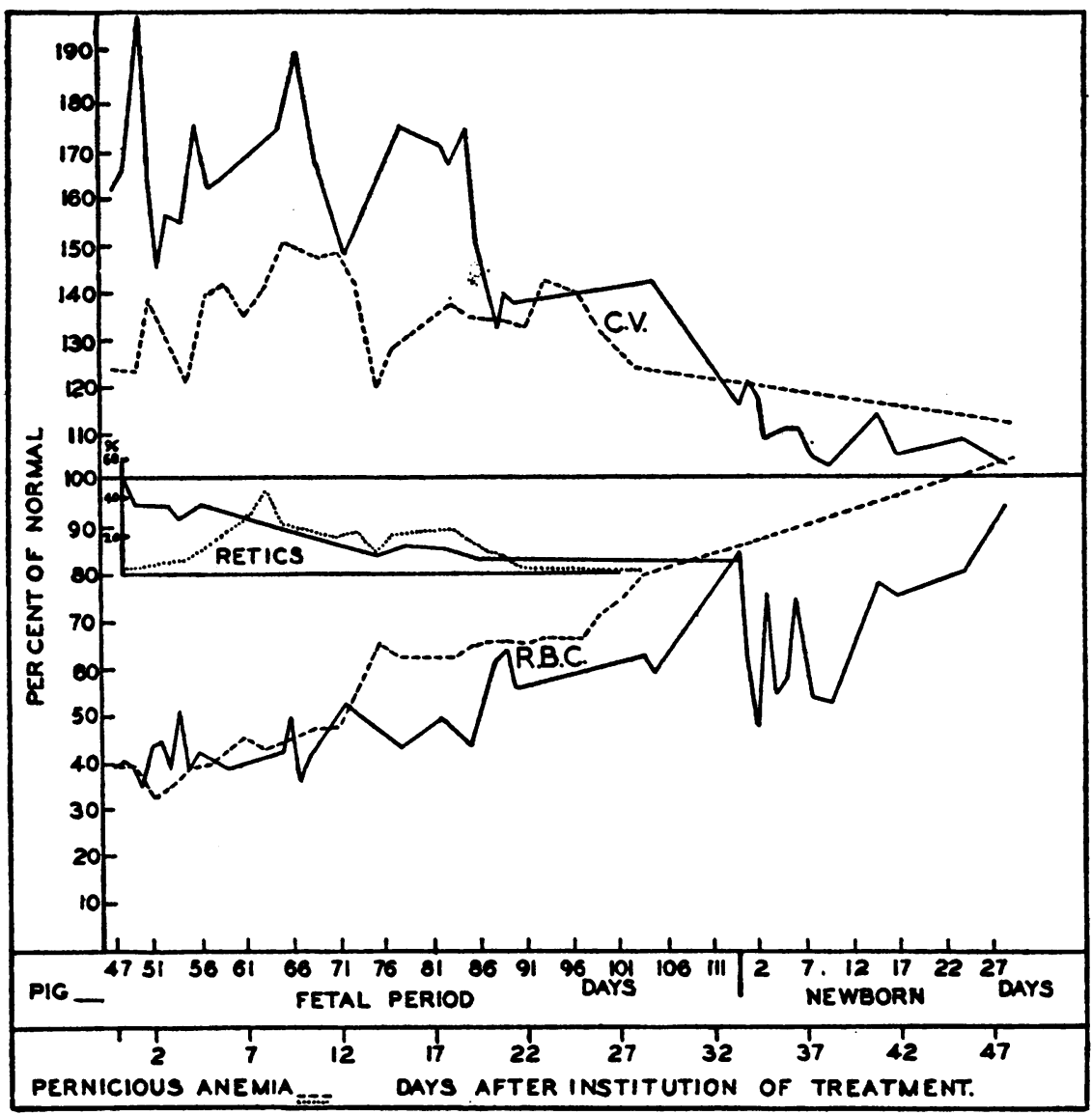

Fig. 6. Comparison of Variations in the Erythrocyte Count (R.B.C.) and Mean Corpuscular Volume (C.V.) of Another Case of Pernictous Anemia Treated with Liver, with Those of Pig Fetuses of Different Ages.

Values are plotted in proportion to the normal for the adult of the species as in Figure 5. The red cell count in this patient was $\mathbf{4 0}$ per cent of normal when treatment was commenced. The curves for the pig fetuses are the same as those shown in Figure 5, but the first portions of these curves up to the point at which the erythrocyte count of the pig fetus had reached $\mathbf{4 0}$ per cent of that of the normal adult pig, have been omitted. The proportion of reticulocytes in the blood of the case of pernicious anemia and in the blood of the pig fetuses are also shown. The complete lines refer to the pig fetuses, the interrupted lines to the case of pernicious anemia. 


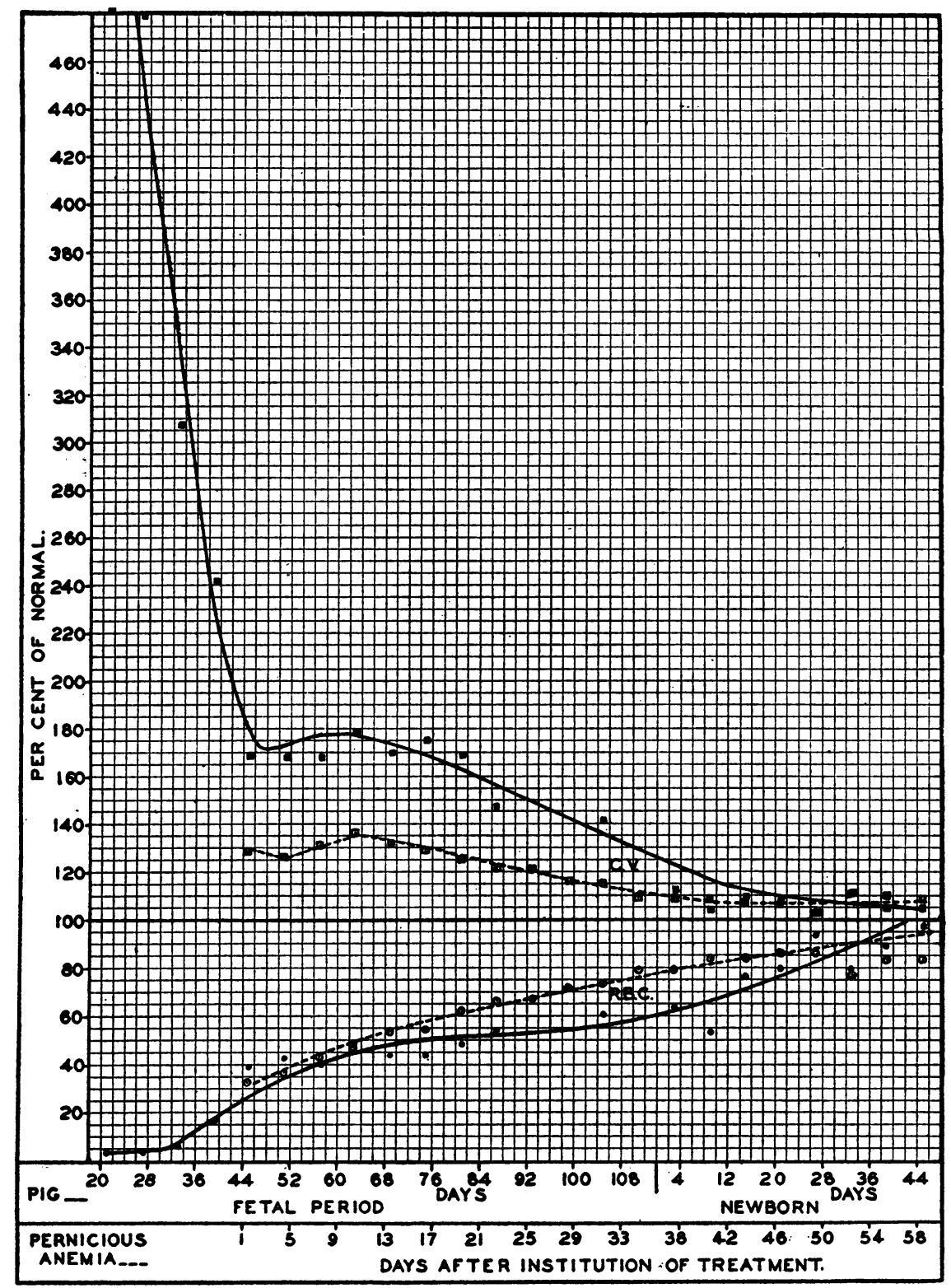

Fig. 7. Smooth Curves for Comparison of the ERythrocyte Count and mean Corpuscular Volume in 98 Pig Fetuses and 22 Newborn Pigs with Those of 9 Cases of Pernicious Anemia Examined Daily During the Response to Liver Therapy (245 Determinations).

The observations in the pigs were grouped according to age in periods of 6 days each and the average for each group calculated. The observations in the cases of pernicious anemia were grouped according to time following the institution of treatment in periods of three days each and the average for each of these groups calculated. The results are plotted in proportion to the normal for the adult of each species (pig, 6.93 million red corpuscles, $59 \mathrm{c} . \mu$. mean corpuscular volume; human, 5.1 million red corpuscles, $87 \mathrm{c.} \mu$. mean corpuscular volume). These averages are shown in the chart as black circles for pig erythrocyte counts and open circles for human erythrocyte counts; black squares for pig mean corpuscular volumes and open squares for human mean corpuscular volumes. The curves were drawn with the aid of a curve rule so that they would fit as well as possible the plotted averages. The complete line curves refer to the pig fetuses and newborn, and the interrupted line curves represent the blood changes in the cases of pernicious anemia. 
diminishes in a manner which again brings to under the influence of liver therapy (Figures 8 mind the changes which occur in pernicious anemia and 9).

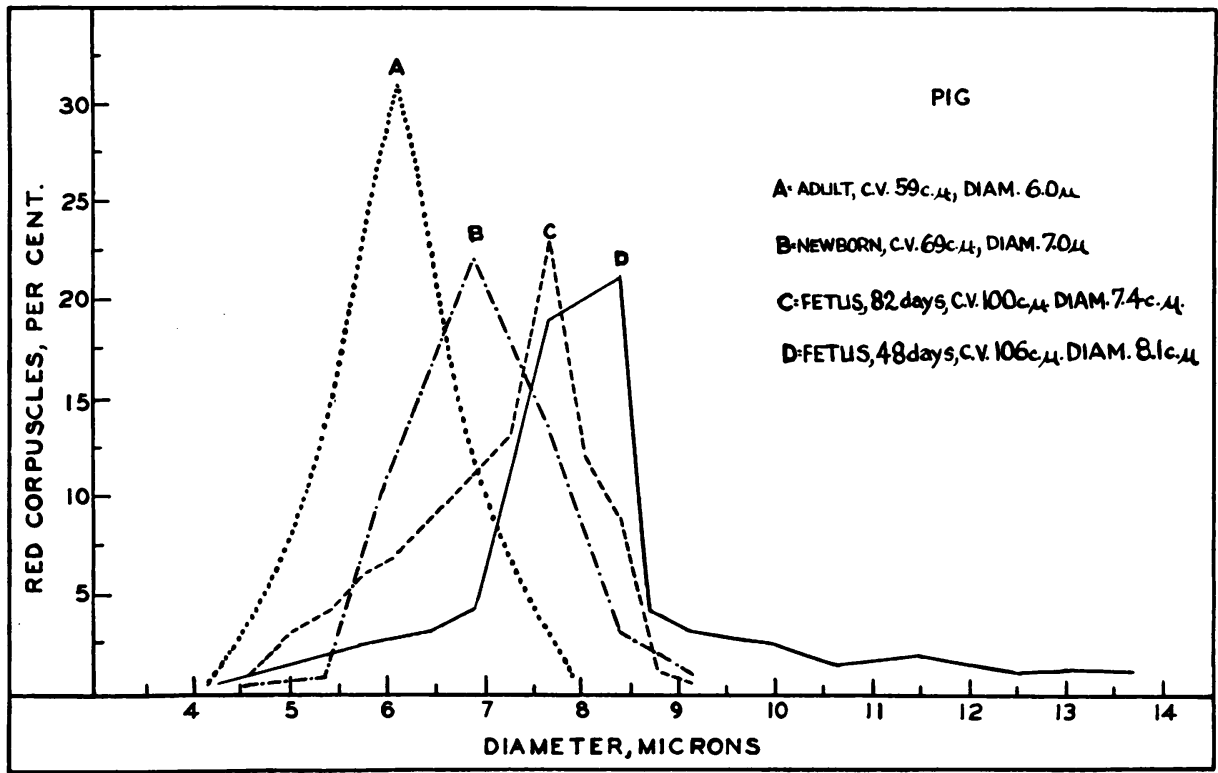

Fig. 8. Distribution of the Diameters of the Red Corpuscles in the Blood of Pig Fetuses Compared with Those of the Blood of the Newborn and the Adult Pig.

Cells measured in fresh (wet) preparations.

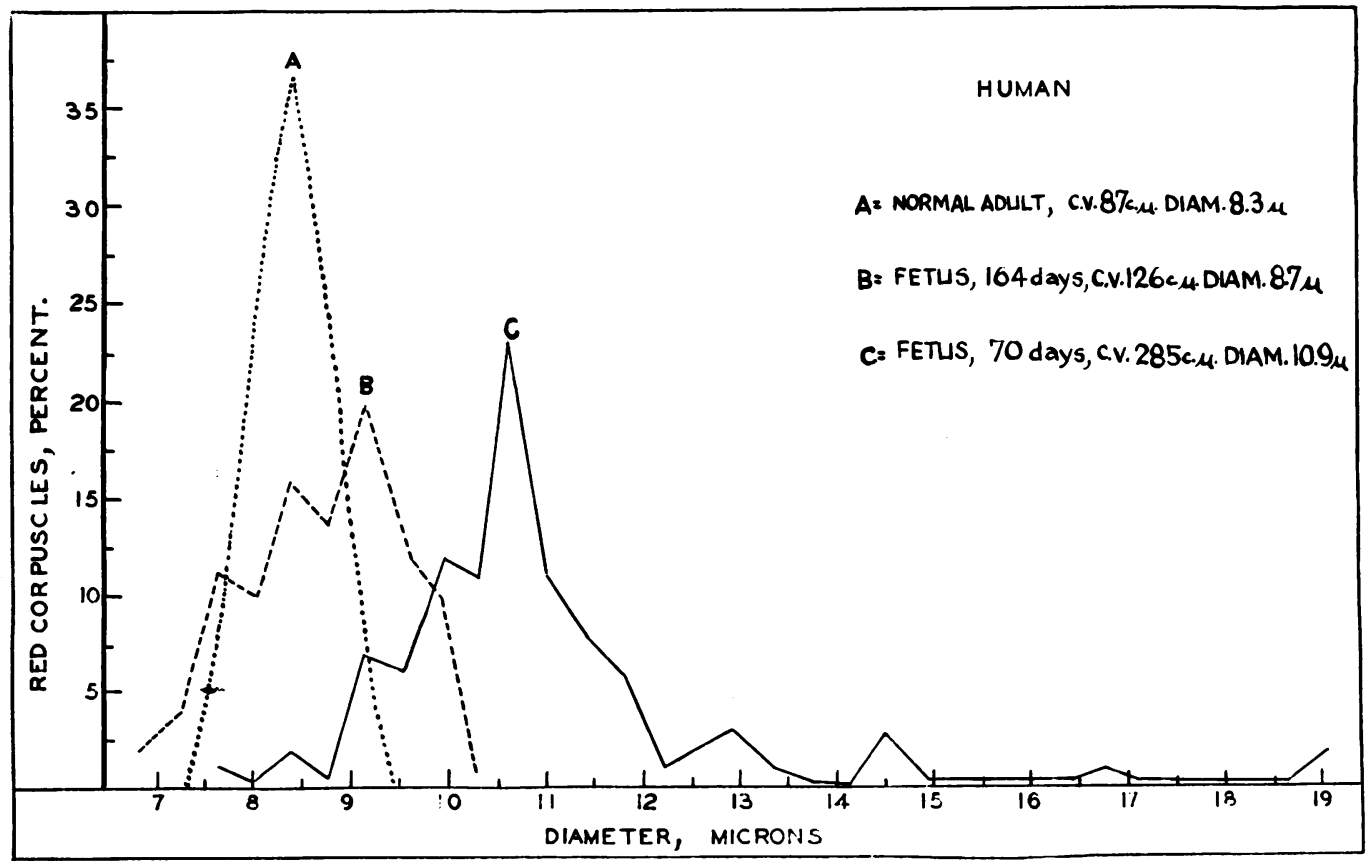

Fig. 9. Distribution of the Diameters of the Red Corpuscles in the Blood of Human Fetuses Compared with the Erythrocytes of the Normal Adult.

Cells measured in fresh (wet) preparations. 
In the smears of fetal blood, numerous erythroblasts were observed and large numbers of polychromatophilic red corpuscles and reticulocytes were found. Macroblasts as well as a number of normoblasts were seen. The nuclei of the red corpuscles were usually small and pyknotic, but occasional cells with larger nuclei composed of reticular chromatin were observed.

The proportion of immature cells found in the blood of the fetuses examined, is indicated in Figures 1, 2, 3, 4 and 6 . In the youngest fetuses observed, all the red corpuscles were nucleated. These erythroblasts lecrease in number very rapidly. The proportion of reticulocytes falls more slowly. In Figure 6 the proportion of reticulocytes in a case of pernicious anemia and in the blood of pig fetuses of various ages are compared. It is of interest to observe that the number of such cells present in the blood of the case of pernicious anemia, from the time liver therapy makes its effects on the reticulocytes noteworthy until normal reticulocyte counts are reached, is approximately the same as in the blood of the pig fetuses. The intensity of blood formation in the pig fetus and in pernicious anemia under the influence of liver therapy, may be compared in another way. In Table I are recorded the number of erythrocytes (Column 2) and the percentage (Column 5) as well as the absolute number (Column 7 ) of reticulocytes in the blood of pig fetuses and newborn pigs of various ages. The proportion which the red cell counts of the fetus form of the red cell count of the adult pig is also shown (Column 3 ). The corresponding human erythrocyte counts have been calculated (Column 4 ). Considering each of the latter counts as the initial erythrocyte counts in cases of pernicious anemia, the maximum percentage of reticulocytes which may be expected following a single dose of liver extract given intravenously, has been calculated for each red cell count according to the formula of Bethell and Goldhamer (26) (Column 6). The expected maximum concentration of reticulocytes has also been calculated in absolute numbers according to the formula of Ninot et al. (27) (Column 8).

Comparison between the values for reticulocytes recorded in Columns 5 and 6 , and in Columns 7 and 8 of Table I, cannot be made unreservedly.

TABLE I

Comparison of reticulocytes in pernicious anemia and in pig fetuses and newborn

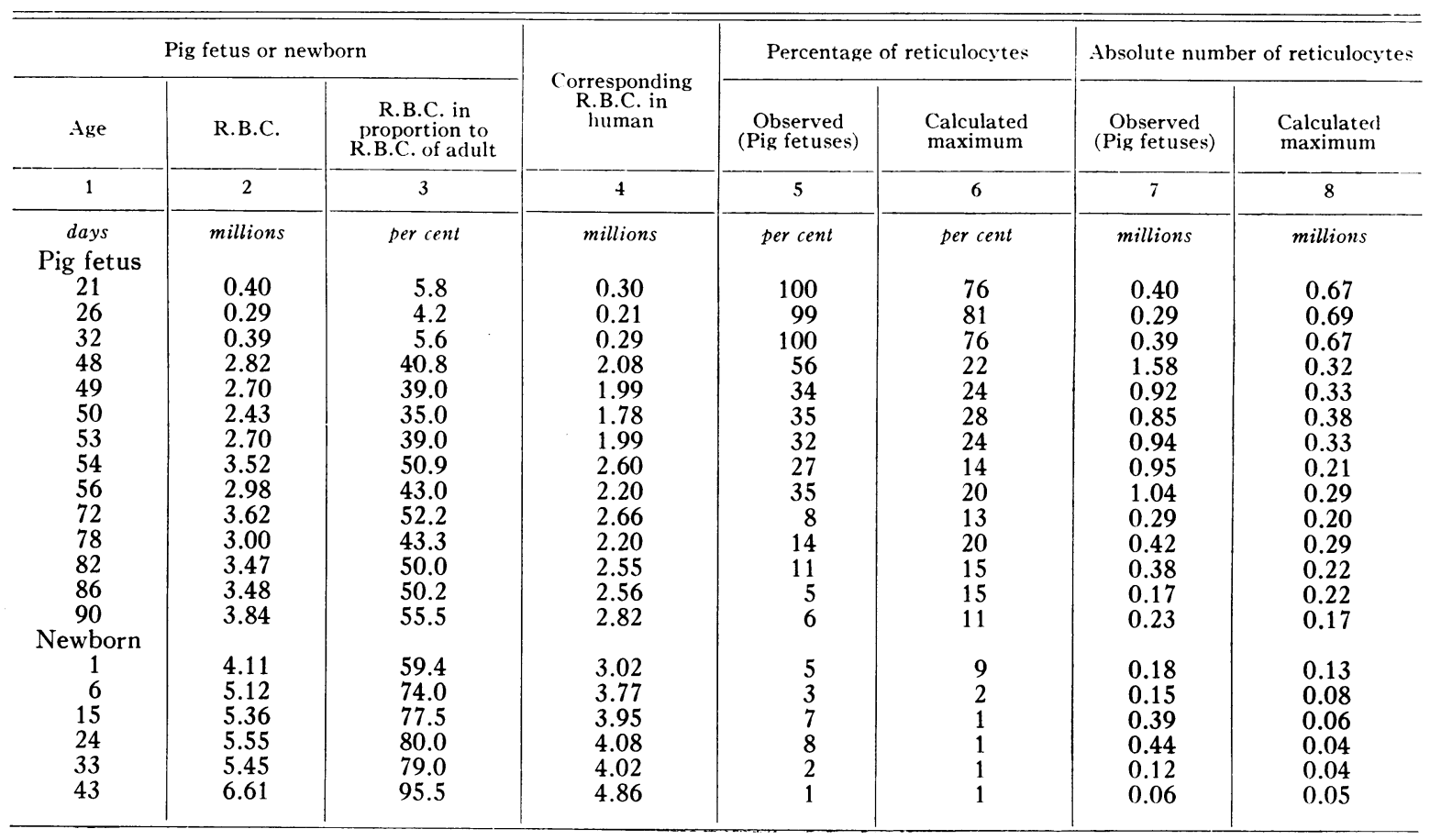


A number of objections to such a comparison come to mind; thus, the calculated reticulocyte counts represent the maximum expected number of reticulocytes in a series of cases of pernicious anemia, and do not indicate the changes which would occur in the blood of a single individual. Again, the formulae for expected reticulocyte response were derived empirically from observations in cases of pernicious anemia in which the reduction in the red cell count was never as low as in some of the instances for which the formulae are here employed. It is evident that the data shown in Table I afford only a very rough comparison; yet it is one which is useful in giving some conception of the intensity of blood formation in the fetus.

Certain points of difference between the blood in cases of pernicious anemia and that of the fetus must be mentioned. Probably the most striking difference is that poikilocytes, although present in fetal blood, are fewer in number, and the extremely bizarre forms so characteristic of Addisonian anemia, are rarely, if ever, found (Figure 10). Again, it is not unusual to find in pernicious anemia a few erythrocytes which are poorly filled with hemoglobin. In the fetal bloods studied such cells were not observed. Finally, as judged by icterus index, blood destruction was no greater in the fetuses of the pig, rabbit, rat, dog and cat than in the adult of each of these species. In the human fetuses, however, the icterus index was usually high, being 25 in two instances, 20 in one, 17 in two and $16,15,12$, and 7 , respectively, in four other fetuses. The Van den Bergh test, carried out in only two of these bloods, gave a strong indirect reaction in one instance in which the icterus index was 25 and a slight indirect reaction in the instance in which the icterus index was 15 .

\section{DISCLSSION}

It is fully appreciated that the morphologic similarity between the blood in cases of pernicious anemia and that of the developing fetus may be but a superficial one, and the agent which influences one set of changes may be quite different from that which leads to the other. Yet the resemblance is so great that comparison seems justified. There is, moreover, similarity in other respects. In the bone marrow of patients dying of pernicious anemia during relapse and in marrow obtained by biopsy at this time, extensive proliferation of primitive cells is found $(28,29)$. The megaloblast of Naegeli is described by him as occurring only in the blood of the early embryo and in that of pernicious anemia (30). Even extramedullary blood formation occurs in pernicious anemia as was first noted by Meyer and Heineke (31) and by Schridde (32). It was, in fact, the finding of foci of extramedullary hematopoiesis in the spleens of some cases of liver disease in which we were interested, and the observation that such foci were associated in most instances with macrocytic anemia (33), that led us to undertake the studies here recorded.

It is our impression, derived from the study of the changes which take place in the size and number of the red corpuscles of the fetus, as well as in the proportion of erythroblasts and reticulocytes, that in many respects the blood of the $d c$ veloping fetus resembles that of cases of pernicious anemia which are being subjected to an effective, continuous and extremely potent stimulus to blood formation.

It would also appear from our studies that the macrocytosis of the newborn, frequently considered to be the result of physicochemical changes in the blood, really represents a final stage in the development of the blood in the fetus. In comparison with the blood in pernicious anemia, the blood of the newborn is similar to that of cases in incomplete remission. An apparent contradiction to this hypothesis is the polycythemia which has been reported in the blood of newborn infants by some investigators (34). Actually, greatly varying results have been recorded (35), and it is doubtful if in the newborn infant which has not become dehydrated, the red cell count is even as high as in the normal adult. In studies made with Eastman and Jack (16) one of us found erythrocyte counts in newborn infants which were slightly lower than the average values for adults. Guest's recent observations on the blood of the human newborn (36) are in exact agreement with our own.

Castle and his associates (37) have demonstrated that pernicious anemia develops as the result of the deficiency of an "antianemic principle" which is formed by the interaction of an 


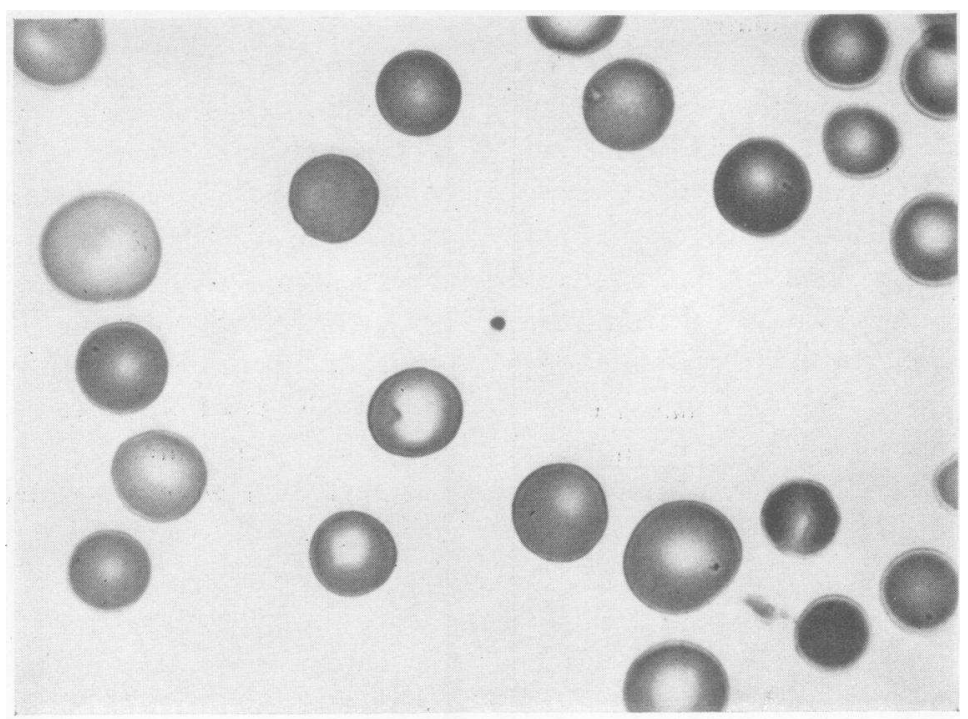

A

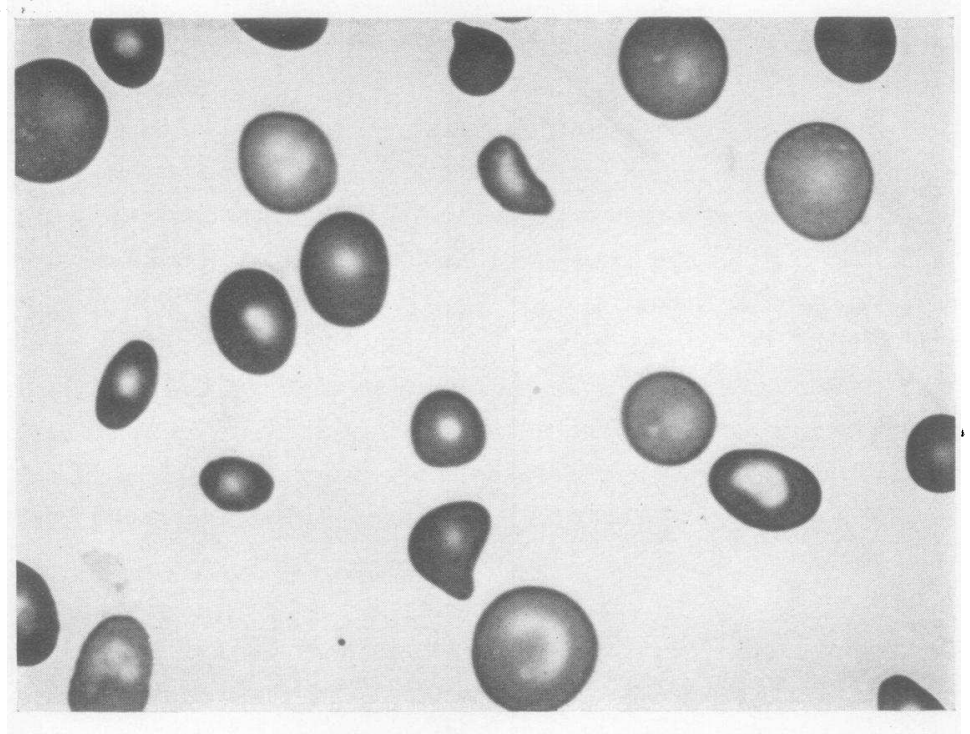

B

Fig. 10. The Blood of a Human Fetes Compared with That of a Case of Perniciols Anemia. Magnification 1170.

A. Human fetus of approximately 98 days. R.B.C. 2.2 million, mean diameter (stained preparation) $8.45 \mu$.

$B$. Pernicious anemia. R.B.C. 1.68 million, mean diameter (stained preparation) $8.21 \mu$. 
"extrinsic factor" in the diet and an "intrinsic factor" secreted by the stomach. It is now well known that the administration of this principle, which is found in greatest concentration in liver, is followed by active blood formation, progressively decreasing macrocytosis and a rapid disappearance of anemia. It seems quite plausible that the antianemic principle of Castle may be the same or very similar to the substance which causes the blood of the fetus to develop in the manner described.

Presumably, there is no gastric digestion in the fetus and no combination of "intrinsic" and "extrinsic" factors takes place as occurs after birth. If a substance similar to Castle's antianemic principle influences the blood of the fetus, it probably comes through the placental circulation from the stores of the mother. It is of interest to point out that antianemic principle has been found not only in the liver, kidney and brain, but also in the placenta (38).

Investigations are in progress which seek to determine whether or not there is any relationship between fetal hematopoiesis and that observed in cases of pernicious anemia treated with liver. The clinical implications of such a relationship, if it can be proved to exist, are of great importance. It is now generally agreed that in Addisonian anemia the degree of anemia is closely dependent on the degree of deficiency of antianemic principle. If there is a similar relationship between the quantity of antianemic principle available and the formation of blood in the fetus, the effect of a deficiency of this substance on the mother and on the infant, may be readily visualized.

If the fetus derives antianemic principle from the mother, this may be expected in some instances to cause so great a depletion in the stores of the mother that she herself develops macrocytic anemia. It is characteristic of the so-called "pernicious anemia" of pregnancy that it develops only during pregnancy, it is relieved by liver therapy, it does not recur following delivery even though liver therapy is discontinued, and it may reappear at a succeeding pregnancy (39). These characteristics conform exactly to what might be expected if the fetus withdraws antianemic principle from the mother. That per- nicious anemia of pregnancy is uncommon, indicates that the majority of pregnant women form, during the normal processes of digestion, quantities of antianemic principle which are adequate to meet their own requirements and those of the fetus. Strauss (39) has observed in cases of macrocytic anemia in pregnancy that the quantity of gastric secretion is often deficient and, in addition, the diet taken by the mother is frequently lacking in animal protein. In these instances the formation of antianemic principle falls below the needs of mother and fetus and macrocytic anemia develops.

An infant for whom an inadequate amount of antianemic principle has been made available during the gestation period, may be expected to develop anemia characterized by macrocytosis and by ready response to the administration of liver extract. Such an anemia might be expected to be more common in premature infants, for these have been afforded a shorter period for the acquisition of antianemic principle, and in twins if they have developed, during the intrauterine period, under conditions in which only a limited amount of antianemic principle is available. If the lack of antianemic principle in the infant is the result of deficient formation of the material by the mother, it would not be unexpected that the resulting anemia would reappear in the progeny of succeeding pregnancies.

That these considerations are not hypothetical is suggested by the experience of pediatricians. Parsons (40) refers to a "primary anemia of the newborn" which is macrocytic in type and "frequently occurs in premature children or in twins and particularly in premature twins." The erythroblastosis of the newborn which has recently received a great deal of attention $(41,42)$ is characterized by familial history, macrocytic anemia, erythroblastosis, increased blood destruction, increased deposition of iron pigment in the tissues and extensive extramedullary foci of blood formation. These findings at once bring pernicious anemia to mind. Liver therapy does not seem to have received serious trial in these cases but it is interesting to note, even though it appears to be an isolated instance, that Bernheim-Karrer and Grob (43) reported successful prophylaxis by the daily feeding of 100 grams of liver during the 
last ten weeks of pregnancy, in a mother who had previously given birth to two infants who died of "icterus gravis." In other types of anemia in infants, liver therapy has been reported as being of value $(44,45)$.

Clinical observations quite analogous to those postulated as associated with deficiency of antianemic principle, have been reported in connection with iron-deficiency anemia in pregnant women and their offspring. Hypochromic microcytic anemia is not uncommon in pregnancy, and is generally considered to be the result of the combined effects of deficient diet, faulty gastric secretion, and the increased requirements for iron due to the needs of the fetus (39). Infants born of mothers with this type of anemia, are not anemic at birth, but they frequently develop moderate to severe degrees of anemia during the first year of life (46). This anemia may be relieved by administering iron to the infants, and it may be prevented by giving iron to the mothers during pregnancy (46).

There is little information concerning the blood of infants born of mothers suffering from either true pernicious anemia or macrocytic anemia of pregnancy. It is generally stated that such infants are not anemic at birth. Even if this is true, it does not necessarily invalidate the hypothesis presented for, in the case of iron deficiency at least, the fetus seems to withdraw iron for blood-building at the expense of the mother and in spite of her increasing anemia.

\section{SUMMARY}

1. Determinations of the erythrocyte count, mean corpuscular volume, mean diameter and proportion of nucleated red corpuscles and reticulocytes in the blood of fetuses and newborn of man, the pig, rabbit and rat, are graphically recorded.

2. It is shown that in very young fetuses of the species examined, the erythrocyte counts are very low and the red corpuscles are very large when compared with the values for red cell count and size in the normal adult of each species. As the fetus develops the erythrocyte count rises, and the red corpuscles become smaller. The proportion of nucleated red corpuscles decreases very rapidly, while the percentage of reticulocytes diminishes more gradually.

3 . In all of the species examined, some macrocytosis was found to be still present at birth; and in the rat, rabbit, pig, cat and dog the erythrocyte count was lower than that of the adult. In man, the erythrocyte count is approximately normal at birth. In the newborn dogs examined, the counts were substantially below the adult values and in the newborn rats they were approximately onethird of those of the mature rat.

These observations suggest that the macrocytosis of the newborn represents a final stage in the normal development of the blood.

4. Comparison is made between the development of the blood in the fetus and the changes which occur in the blood of cases of pernicious anemia in response to liver therapy.

5. The blood of the fetus resembles in many respects that of cases of pernicious anemia which are being subjected to an effective, continuous and extremely potent stimulus to blood formation.

6. It is suggested that the antianemic principle of Castle may be responsible for the described changes in the blood of the fetus, and that this principle passes to the fetus from the stores of the mother. On this hypothesis it is possible to visualize the mode of development of "pernicious anemia" of pregnancy. The significance of this conception in regard to anemia in infants is also considered.

We are indebted to Dr. I. P. Earle and to Mr. J. H. Zeller of the U. S. Research Center, Beltsville, Maryland, for securing for us blood from newborn pigs; and to Messrs. William J. Schmidt and William A. Oktavec, Jr., as well as Miss Mary Smith, for technical assistance. Mr. Milton Kougel made the microphotographs.

\section{BIBLIOGRAPHY}

1. Malassez, L., Recherches sur quelques variations que présente la masse totale du sang. Arch. f. d. ges. Physiol., 1875, 2, 261.

2. Cohnstein, J., and Zuntz, N., Untersuchungen über das Blut, den Kreislauf und die Athmung beim Säugethier-Fötus. Arch. f. d. ges. Physiol., 1884, 34, 173.

3. Malassez, L., Sur la mensuration des globules sanguins, règle globulimétrique. Compt. rend. Soc. de biol., 1889, 1, 2. 
4. Milne-Edwards, Leçons sur la physiologie, 1857, I, p. 53. Quoted by Jolly, J., Traité technique d'Hématologie. I. A. Maloine et Fils, Paris, 1923, p. 131.

5. Jolly, J., Variations du nombre des globules rouges du sang au cours du développement. Compt. rend. Soc. de biol., 1906, 1, 564.

6. Jolly, J., Variations de l'hémoglobine, du nombre des globules rouges et de la valeur globulaire aux différentes périodes de la vie, chez le rat blanc. Compt. rend. Soc. de biol., 1909, 1, 137.

7. Nicholas, J. S., and Bosworth, E. B., The determination of the amount of hemoglobin present in rat fetuses during development. Am. J. Physiol., 1927-28, 83, 499.

8. Kindred, J. E., and Corey, E. L., Studies on the blood of the fetal albino rat. Anat, Record, 1930, 47, 213.

9. Smith, C., The post-embryonic development of the erythrocytes of the albino rat. J. Path. and Bact., 1932, 35, 717.

10. Knoll, W., Blut und blutbildende Organe menschlicher Embryonen. (Denkschriften d. Schweiz. Naturforsch. Ges. Bd. 64, Abh. 1). Zürich: Gebr. Fretz A.-G. 1927.

11. Knoll, W., Untersuchungen über embryonale Blutbildung beim Menschen. Ztschr. f. mikr.-anat. Forsch., 1929, 18, 199.

12. Zeidberg, L. D., A quantitative determination of the changes in hemoglobin concentration, volume of red cells, and basophilia in the blood of rabbit fetuses at various stages during the last third of pregnancy. Am. J. Physiol., 1929, 90, 172.

13. von Deseö, D., Beitrag zur Kenntnis der fetalen Blutentwicklung beim Rinde. Arch. f. d. ges. Physiol., 1929, 221, 326.

14. Keibel, F., and Mall, F. P., Manual of human embryology. I. J. B. Lippincott Co., Philadelphia, 1910, p. 200.

15. Streeter, G. L., Weight, sitting height, head size, foot length and menstrual age of the human embryo. Contributions to embryology. XI. Carnegie Institute of Washington, 1920, Pub. No. 274.

16. Wintrobe, M. M., Eastman, N. J., and Jack, R. W., Unpublished observations.

17. Donaldson, H. H., The Rat. Wistar Institute, Philadelphia, 1924, p. 173.

18. Wintrobe, M. M., Shumacker, H. B., Jr., and Schmidt, W. J., Values for number, size and hemoglobin content of erythrocytes in normal dogs, rabbits and rats. Am. J. Physiol. (In press.)

19. Warwick, B. L., Prenatal growth of swine. J. Morphol., 1928, 46, 59.

20. Windle, W. F., and Griffin, A. M., Observations on embryonic and fetal movements of the cat. J. Comp. Neurol., 1931, 52, 149.

21. Coronios, J. D., Development of behavior in the fetal cat. Genetic Psychology Monographs, 1933, 14, 283.
22. Wintrobe, M. M., The size and hemoglobin content of the erythrocyte. J. Lab. and Clin. Med., 1932, 17, 899.

23. Wintrobe, M. M., Anemia. Classification and treatment on the basis of differences in the average volume and hemoglobin content of the red corpuscles. Arch. Int. Med., 1934, 54, 256.

24. Wintrobe, M. M., and Shumacker, H. B., Jr., Erythrocyte studies in the mammalian fetus and newborn. Am. J. Anat. (To be published.)

25. Wintrobe, M. M., Relation of variations in mean corpuscular volume to number of reticulocytes in pernicious anemia. The significance of increased bone marrow activity in determining the mean size of red corpuscles. J. Clin. Invest., 1934, 13, 669.

26. Bethell, F. H., and Goldhamer, S. M., Standards for maximum reticulocyte values following ventriculin and intravenous liver extract therapy in pernicious anemia. Am. J. M. Sc., 1933, 186, 480.

27. Minot, G. R., Cohn, E. J., Murphy, W. P., and Lawson, H. A., Treatment of pernicious anemia with liver extract. Am. J. M. Sc., 1928, 175, 599.

28. Zadek, I., Blut- und Knochenmarksbefunde am Lebedenden bei Kryptogenetischer perniciöser Anämie, insbesondere im Stadium der Remission. Ztschr. f. klin. Med., 1922, 95, 66.

29. Peabody, F. W., The pathology of the bone marrow in pernicious anemia. Am. J. Path., 1927, 3, 179.

30. Naegeli, O., Blutkrankheiten und Blutdiagnostik. Julius Springer, Berlin, 1931, p. 98.

31. Meyer, E., and Heineke, A., Ueber Blutbildung in Milz und Leber bei Schweren Anämien. Verhandl. d. deutsch. path. Gesellsch., 1905, 9, 224.

32. Schridde, H., Ueber Regeneration des Blutes unter Normalen u. Krankhaften Verhältnissen. Centralbl. f. allg. Path. u. path. Anat., 1908, 14, 865.

33. Wintrobe, M. M., The relation of disease of the liver to anemia. Arch. Int. Med. (In press.)

34. Wintrobe, M. M., The erythrocyte in man. Medicine, 1930, 9, 195.

35. Merritt, K. K., and Davidson, L. T., The blood during the first year of life. Am. J. Dis. Child., 1933, 46, 990.

36. Guest, G. M., Personal communication.

37. Castle, W. B., Townsend, W. C., and Heath, C. W., Observations on the etiologic relationship of achylia gastrica to pernicious anemia. Am. J. M. Sc., 1929, 178, 748 and 764. Ibid., 1930, 180, 305.

38. Minot, G. R., The development of liver therapy in pernicious anemia. Lancet, 1935, 1, 361.

39. Strauss, M. B., The etiology and treatment of anemia in pregnancy. J. A. M. A., 1934, 102, 281.

40. Parsons, L. G., The anemias of infancy and early childhood. J. A. M. A., 1931, 97, 973.

41. Abt, A. F., Erythroblastosis in icterus gravis neonatorum. J. Pediat., 1933, 3, 7.

42. Hawksley, J. C., and Lightwood, R., A contribution to the study of erythroblastosis: icterus gravis neonatorum. Quart. J. Med., n.s., 1934, 3, 155. 
43. Bernheim-Karrer, J., and Grob, M., Zur Prophylaxe des Icterus neonatorum gravis. Ztschr. $\mathbf{f}$. Kinderh., $1931,50,672$.

44. Hampson, A. C., and Warner, E. C., Anemia and liver therapy in infancy and childhood. Arch. Dis. Child., 1930, 5, 299.
45. Maurer, S., Greengard, J., and Kluver, C., The value of liver extract and iron in the anemia of young infants. J. A. M. A., 1932, 98, 1069.

46. Strauss, M. B., Anemia of infancy from maternal iron deficiency in pregnancy. J. Clin. Invest., 1933, $12,345$. 